\title{
KARMA BİR KARAR VERME YAKLAŞIMI İLE ELEKTRİK İLETİM HATTI İÇİN GÜZERGÂH SEÇIMI
}

\author{
${ }^{1}$ Mehmet Emin BAYSAL, ${ }^{2}$ Musa AYDIN, ${ }^{3}$ Ahmet SARUCAN \\ 1,3Selçuk Üniversitesi Müh. Mim. Fak. Endüstri Mühendisliği Bl., 42250 Konya \\ ${ }^{2}$ Selçuk Üniversitesi Müh. Mim. Fak. Elektrik-Elektronik Müh. Bl., 42250 Konya \\ ${ }^{1}$ mebaysal@gmail.com, ${ }^{2}$ aydin@selcuk.edu.tr, ${ }^{3}$ sarucan@gmail.com
}

(Geliş/Received: 22.01.2015 ; Kabul/Accepted in Revised Form: 16.03.2015)

\begin{abstract}
ÖZET: Hızla artan nüfus ve enerji kullanımı, beraberinde yeni elektrik iletim hatlarının oluşturulması ihtiyacını getirmektedir. Bir elektrik iletim hattının güzergâh seçimi için alternatiflerin değerlendirilmesinde, mühendislik ihtiyaçları, mamur alan, doğal çevre vb. belirli kriterler göz önüne alındığından, çok kriterli karar verme (ÇKKV) problemi ortaya çıkar. Bu çalışmada ÇKKV problemlerinin çözümünde etkin olarak kullanılan Analitik Ağ Süreci (AAS) yaklaşımı kullanılmıştır. Bu amaç doğrultusunda, Selçuk Üniversitesi Alâeddin Keykubat Yerleşkesi içinden geçirilecek bir elektrik iletim hattının alternatif geçiş yollarının değerlendirilmesine yönelik bir uygulama sunulmuştur. Elektrik iletim hattı için AAS belirlenen kriterlere göre makro koridorlar oluşturulmuş ve Faktör Ağırlıklandırma (FA) Yöntemi kullanılarak almış oldukları en yüksek puana göre en iyi alternatif güzergâh seçilmiştir.
\end{abstract}

Anahtar Kelimeler: Elektrik İletim Hattı, Analitik Ağ Süreci, Faktör Ağırlıklandırma Yöntemi

\section{ELECTRICITY TRANSMISSION LINE ROUTE SELECTION BY AN INTEGRATED MULTI- CRITERIA DECISION MAKING METHODOLOGY}

ABSTRACT: The needs of building new electricity transmission lines grow up due to rapid pace of population and energy usage. Since it is considered certain criteria such as engineering requirements, built environment and natural environment for the evaluation of alternatives to select the best route for the new transmission line, the problem is multi-criteria decision making problem (MCDM). In this study, the Analytic Network Process (ANP) which is an efficient technique in the solution of the MCDM problems was used. In line with this aim, it was presented an evaluation of alternative routes for the application of a new electricity transmission line passing through the campus area of the Selcuk University. It was determined the macro corridors based on ANP and then the best route was picked up from alternatives according to their scores figured out by using Factor Weighting Method (FWM).

Keywords: Electricity Transmission Line, Analytic Network Process, Factor Weighting Method

\section{GİRIŞ (INTRODUCTION)}

Elektrik nakil hattı, elektrik santralinde kontrollü ve planlı olarak elde edilmiş elektrik enerjisinin, santrallerden dağıtım hatlarına iletilmesini sağlar. Elektrik nakil hattı, elektrik üretim tesisleri ile transformatör istasyonları; transformatör istasyonları ile son tüketici arasında elektrik enerjisi iletimini sağlayan sistemdir. Elektrik hatları döşeme güzergahının seçiminde; maliyet, iletim hattının güzergâhı, coğrafi konum, arazi durumu, hattın güvenlik durumu gibi kriterler dikkate alınır. 
Son yıllarda meydana gelen nüfus artışları ve teknolojik gelişmelerle artan elektrik enerjisi ihtiyacının karşılanabilmesi için yeni üretim tesislerinin kurulması ve nakil hatlarının yeniden düzenlenmesi gerekmektedir. Enerji nakil hattı güzergâhı belirlenirken sosyal, teknik, çevresel, ekonomik etkenler göz önünde bulundurularak en uygun yolun seçilmesi gerekmektedir. Pek çok kriterin bir arada değerlendirilmesinden dolayı güzergâh seçimi karmaşık mühendislik problemlerinden birisidir. ÇKKV probleminde birden fazla alternatifler iki veya daha fazla kriterlerle değerlendirilmektedir. Çalışmada elektrik iletim hattı güzergah seçiminde, 3 ana kriter ve 16 alt kriter kullanılmıştır.

Enerji nakil hatlarında güzergâh seçimi ile ilgili literatürde son yıllarda yapılan çalışmalar aşağıda özetlenilmiştir.

Gill ve diğerleri [1] elektrik iletim hatlarının güzergâh seçimi problemi için, disiplinler arası yeni bir yöntem önermişlerdir. Çalışmada, coğrafik özelliklerin iletim hattı güzergâh seçimini etkilediği ifade edilmiştir. Yüksek gerilim hattının güzergâhını etkileyecek ana kriterler tespit edilmiş ve bu kriterler üç kategoride sınıflandırılmıştır: sosyoekonomik, çevre ve sağlık-güvenlik kriterleridir. Jewell ve diğerleri [2], enerji nakil hattı güzergâhı seçimine, kamunun katılımını sağlamak için yeni bir yöntem önermişlerdir. Bu yöntemin yeni oluşturulacak nakil hatlarına kamu muhalefetini azaltacağı ve bu nedenle yeni hattın inşaatı ve onayı için gerekli olan zamanın kısalacağı ifade edilmiştir. Coğrafi bilgi sistemi (CBS) araçları kullanılarak desteklenen bu yeni yöntemin, mevcut yöntemlerden daha etkili olduğunu düşünülmüştür. Selçuk Üniversitesi yerleşke alanında enerji nakil hatlarının optimizasyonu ile ilgili, Demircan [3] tarafından bir araştırma yapılmıştır. Çalışmada farklı kriterlere göre coğrafi bilgi sistemleri kullanılarak Q-öğrenme tabanlı bir algoritma kullanılmıştır. Kriterler farklı olduğu için Demircan tarafından elde edilen sonuçların, bu araştırma ile kıyaslanması mümkün olmamıştır.

$\mathrm{Bu}$ çalışmada ise Selçuk Üniversitesi, Alâeddin Keykubad Yerleşkesinde elektrik nakil hattı güzergâh seçiminde, AAS kullanılmıştır. Araştırmada, arazi yapısı, çevresel faktörler ve yasak bölgeler ana kriter olarak dikkate alınmış ve bu ana kriterlere bağlı oniki alt kriter ağırlıklandırılarak uygun güzergah belirlenmesi FA yöntemi ile yapılmıştır.

Çalışmanın ikinci bölümünde, AAS ve Faktör Ağırlıklandırma yöntemi açılanmıştır. Üçüncü bölümde, elektrik iletim hattı güzergâh seçiminde AAS yöntemi ve Faktör Ağırlıklandırma yöntemi ile yapılan uygulama anlatılmıştır. Dördüncü bölümde ise elde elden sonuçlar tartışılmıştır.

\section{METODOLOJİ (METHODOLOGY)}

\subsection{Analitik A $\breve{g}$ Süreci (Analytical Network Process-ANP)}

Çok ölçütlü karar probleminde; amaç, kriterler, alt kriterler ve alternatifler arasında bağımlılıklar, karşılıklı ilişkiler ve geri bildirimler mevcuttur. Bu durumda problemi hiyerarşik olarak modellemekten ziyade ağ (şebeke) halinde yapılandırmak gerekir. A $\breve{g}$ modellerinde sadece kriterlerin önemi alternatiflerin önemini belirlemez, aynı zamanda alternatiflerin önemi de kriterlerin önemini belirleyebilir. Bu tip karmaşık ilişkili problemlerin çözümünde kullanılmak üzere, Saaty [4] tarafından AAS olarak adlandırılan yöntem geliştirilmiştir.

AAS'de, iki yönlü ok, seviyeler arasındaki iç bağımlılığı, döngü şeklindeki ok ise aynı seviye ilişkilerdeki bağımlılığı göstermek için kullanılır. İç bağımlılıklar birçok şekilde meydana gelebilir. AAS ile karar problemlerinin çözümünde Şekil 1'deki adımlar uygulanır [5-16]: Adım 1'de, AAS hiyerarşik bir ağ yapısına sahip olduğundan, süper ve alt matrisleri oluşturmak için araştırma problemini açıça tanımlanır ve ağ şeklinde ayrıştırılır. Adım 2'de kriterlerin önem ağırlıklarını belirlemek için; ikili karşılaştırmalar matrisi oluşturulur. AAS' de ikili karşılaştırma matrislerinin oluşturulmasında, Saaty [4] tarafından önerilen, 1-9 önem skalası kullanılır. Adım 3'de süper matris oluşturulur. Süper-matris, Markov zinciri sürecine benzerdir. Süper matris oluşturma sürecinde, birbirine bağımlı etkiler, yerel öncelik vektörleri, küresel önceliklerin elde edilmesi için, süper matrisin sütunlarına eklenir. Bu durumda süper matris, her matris segmentini temsil eden parçalı bir matris olur. 


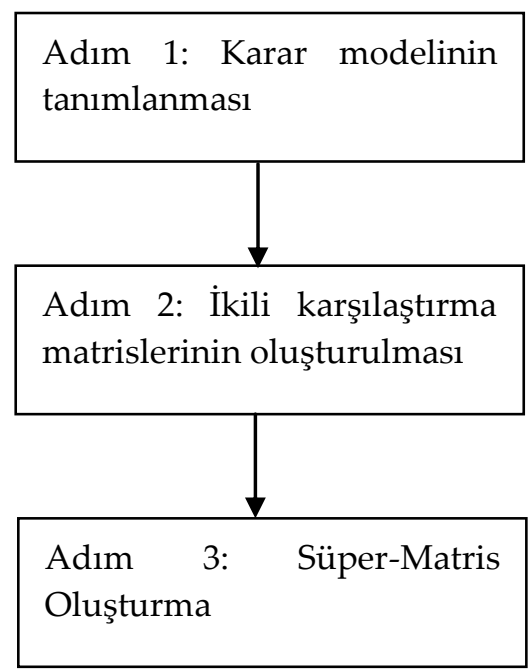

Şekil 1. AAS ile Çözüm Adımları (Solution Steps by ANP)

\subsection{Faktör Ağırlıklandırma Yöntemi (Weighted Factors Method)}

Alınması gereken kararı etkileyen kriterlerin çeşitli ve bazılarının sayısal olmadığı durumlarda Faktör Ağırlıklandırma Yöntemi kullanılır [17].

Faktör ağırlıklandırma, 6 adıma sahip basit sayısal bir yöntemdir:

1) İlgili kriterlerin bir listesi oluşturulur.

2) Her bir kritere, firmanın amaçlarındaki nispi önemini yansıtacak şekilde bir ağırlık atanır.

3) Her bir kriter için bir skala geliştirilir (örneğin 1-5, 1-10 ya da 1-100 puanları).

4) Her bir alternatife, her bir kriter için adım 3 deki skala uygulanarak skor belirlenir.

5) Her bir kriter için ağırlıkları skorla çarpılır ve her bir alternatif için toplam skor bulunur.

6) Toplam skoru en fazla olan alternatif önerilir.

\section{ELEKTRIKK İLETIM HATTININ SEÇILMESINNDE ANALITIK ŞEBEKE SÜRECININ KULLANIMI (THE USAGE OF ANALYATIC NETWORK PROCESS FOR THE SELECTION OF ELECTRICITY TRANSMISSION LINE)}

Bu çalışmada karma bir karar verme yaklaşımı, Selçuk Üniversitesi elektrik dağıtım hattının seçilmesinde kullanılarak belirlenen alternatif güzergâhlar arasından en uygun olanı belirlenmiştir. Çalışmaya, elektrik dağıtım hattı problemleri konusunda uzman bir ekip kurularak başlanılmıştır. Bu ekip tarafından çalışmanın hassas alanları stadyum, ibadet alanları, kütüphane, okul binaları vb. alanlar seçilerek problemin çözüm adımları aşağıdaki gibi oluşturulmuştur [18]:

1- Makro koridorların belirlenmesi

2- Alternatif koridorların belirlenmesi

3- Faktör ağırlıklarının belirlenmesinde AAS uygulanması

4- Alternatif güzergahların belirlenmesi

5- Alternatif güzergahların değerlendirilmesi

\subsection{Makro Koridorların Belirlenmesi (Macro Corridors Generation)}

Çalışmanın ilk aşaması, uzman ekip tarafından beyin fırtınası yapılarak makro koridorların belirlenmesidir. Birinci koridor mevcut dağıtım hattına paralel seçilir. İkinci koridor yola paralel olarak 
seçilir ve üçüncü koridor Kampus alanının ortasından geçecek şekilde seçilir. Bu üç koridorun tespiti ile projenin sınırları belirlenir. Şekil 2'de çalışma alanı olarak seçilen Selçuk Üniversitesi Yerleşkesinin görünümü ve oluşturulan makro koridorlar görülmektedir.

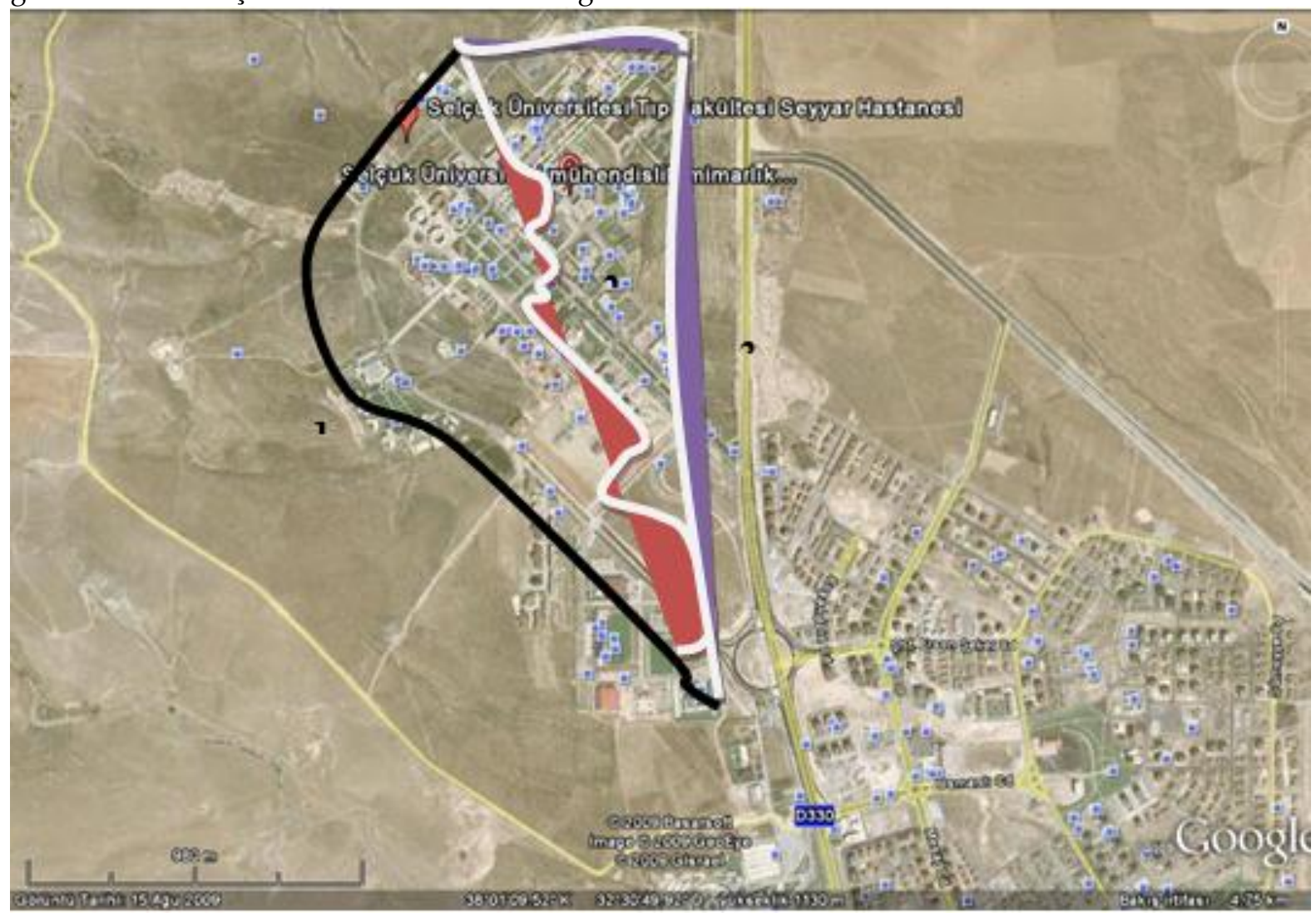

Şekil 2. Macro Koridorlar (Macro Corridors)

\subsection{Alternatif Koridorların Belirlenmesi (Alternative Corridors Generation)}

Birinci aşamada makro koridorlar oluşturularak çalışma alanı belirlenmiştir. İkinci aşamada ise makro koridorlar içerisinden alternatif koridorlar oluşturulmuștur. Koridorların belirlenmesinde mühendislik faaliyetleri, çevresel faktörler, yasak bölgeler, arazi yapısı gibi ana kriterler dikkate alınabilir [3].

Alternatifleri standartlaştırmak için kriter ve alt kriterler uzman ekip ve literatür çalışması sonunda Çizelge 1'deki gibi belirlenmiş ve kriterlerin ağırlıklarının hesaplanmasında AAS kullanılmıştır.

\subsection{Kriter Ağırlıklarının Belirlenmesinde Analitik A $\breve{g}$ Sürecinin Uygulanması (The Determination of Factors Weights by Using ANP)}

Adım 1: Problemin tanımlanması ve modelin kurulması (The Definiton of the problem and formulation of the model)

Alternatif koridorların tespit edilmesinde kullanılacak kriterlerin ağırlıklarının belirlenmesi AAS yöntemi ile gerçekleştirilmiştir. Çizelge 1'deki veriler kullanılarak Şekil 3'deki gibi bir ağ modeli kurulmuştur. Problem, binaların korunması, doğal çevrenin korunması ve mühendislik ihtiyaçları olmak üzere üç ana kriter altında incelenmiştir.

Adım 2: İkili Karşılaştırma Matrisleri ve Öncelik Vektörleri (Pairwise Comparison Matrices and Priority Vectors) 
A ğ yapısı oluşturulduktan sonra ikili karşılaştırmaların gerçekleştirilmesi ve kriterlerin öz vektör değerleri veya diğer bir deyişle etki değerlerinin hesaplanması gerekir. Hesaplanan bu değerler süper matriste ilgili kısımlara yerleştirilir.

Çizelge 1. Problemin Kriter ve Alt Kriterleri (Factors and Sub-Factors for the Problem)

\begin{tabular}{|c|c|}
\hline Kriterler & Alt Kriterler \\
\hline \multirow{4}{*}{$\begin{array}{l}\text { Mühendislik } \\
\text { Faaliyetleri }\end{array}$} & Düzgün Altyap1 \\
\hline & Ĕ̆itim \\
\hline & Ĕ̆im-Kırrılma Açısı \\
\hline & Yoğun Tarım \\
\hline \multirow{7}{*}{$\begin{array}{l}\text { Binaların } \\
\text { Korunması }\end{array}$} & Alan Kullanımı \\
\hline & Bina Yoğunluğu \\
\hline & Binalara Yakınlık \\
\hline & Gelişime Açık Bölgeler \\
\hline & Gelişmeye Açık Gölet \\
\hline & Tarihi Yapılar \\
\hline & Önemli Hatlara Yakınlık \\
\hline \multirow{5}{*}{$\begin{array}{c}\text { Doğal Çevrenin } \\
\text { Korunması }\end{array}$} & Halka Açık Alanlar \\
\hline & Hayvan Koruma Alanlar \\
\hline & Kapalı Alanlar \\
\hline & Sel Havzası \\
\hline & Su Adası \\
\hline
\end{tabular}

Elektrik İletim Hattı İçin

Ağırlıkların Belirlenmesi
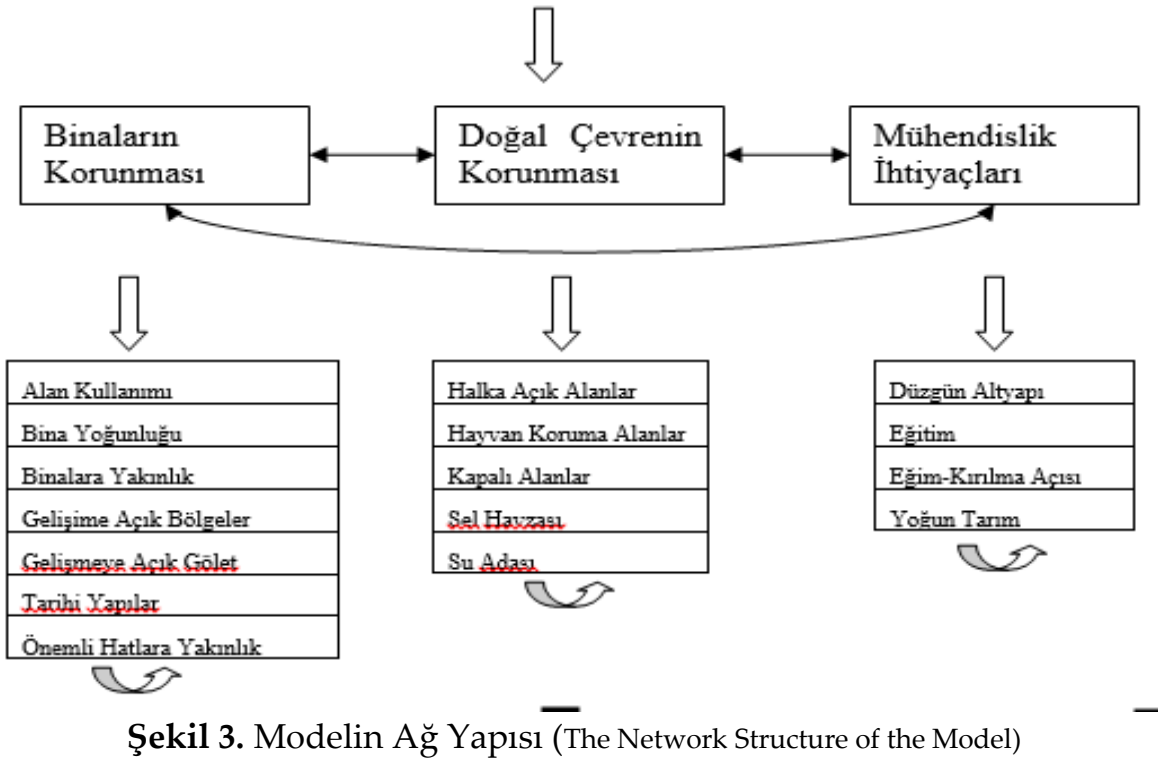

İkili karşılaştırmalar üç temel aşamada ele alınmıştır. Birinci aşamada; kriter kümeleri birbirleri ile karşılaştırılmış, ikinci aşamada; kriterler iç ve dış bağımlılıklarına göre karşılaştırılmış ve son aşamada alternatifler tek tek kriterlere göre karşılaştırılmıştır. 
Birinci aşamada kriter kümelerinin ağırlıkları hesaplanmıştır. Bu ilk aşamada kümeler arasında herhangi bir etkileşimin olmadığı düşünülerek, kümelerin amaçla ilgili olarak birbirlerine göre önem düzeyleri eşit kabul edilmiştir. Başka bir ifadeyle elektrik dağıtım hattı seçiminde bütün kriterler eşdeğer öneme sahip kabul edilmiştir.

Aynı şekilde diğer kriter kümelerini baz alarak elde edilen küme ağırlıkları hesaplanmış ve her bir matrisin tutarlılık oranı 0,1 değerinden düşük çıkmıştır. Bu oranın 0,1 değerinden düşük çıkması, oluşturulan ikili karşılaştırmalar matrisine göre bulunan ağırlık değerlerinin karar vermede kullanılabileceğini göstermektedir.

Elde edilen küme ağırlıkları süpermatrisin sütunlarının stokastik yapıya dönüştürülmesinde kullanılmıştır. Bu işlem yapılırken, elde edilen ağırlıklandırılmamış süpermatristeki kriterlerin öz vektör değerleri, küme ağırlıkları matrisindeki değerler ile çarpılarak ağırlıklandırma yapılmıştır. Birinci aşamanın başında küme ağırlıkları elde edildikten sonra kümelerin içerisindeki kriterlerin kendi kriter kümesi ile ilgili olarak öz vektör değerleri hesap edilmiştir. Buradan elde edilecek değerler süpermatrisin amaç sütununda yerini almıştır.

Kriter kümelerinin ve kriterlerin amaç açısından öz vektör değerleri bulunduktan sonra ikinci aşamada, kriterlerin birbirleri üzerindeki etkileri ve bu etkilerin önem düzeyleri bulunmuştur. Bu etki düzeylerinin belirlenmesi ile amaca ulaşabilmek için hangi kriterin daha önemli olduğu ayrıntılı olarak incelenmiş̧ir. Kriterlerin birbirleri arasındaki karşılıklı etkileşimlerinin belirlenmesi de iç bağımlılık ve dış bağımlılığa göre değerlendirilmiştir. İç ve diş bağımlılıklarla ilgili olarak değerler elde edildikten sonra kümeler arası etkileşimler incelenerek ağırlıklar tespit edilmiş ve bu ağırlıklar ile süper matris oluşturmuştur.

İç Bağımlılıklar (Internal Dependencies)

Elde edilen şebeke yapısında aynı küme içinde birbirini etkileyen kriterler mevcutsa bu kriterlerin iç bağımlılık adı altında ağırlıklarının belirlenmesi gerekmektedir. Değerlendirme yapılırken, bir kriteri aynı küme içindeki sadece bir kriter etkiliyorsa etki düzeyi 1 olarak alınır. Birden fazla kriter etkiliyorsa ikili karşılaştırma yapılarak etki düzeyleri belirlenir.

Dış Bağımlılıklar (External Dependencies)

İç bağımlılıkların öz vektör değerleri belirlendikten sonra, sıra kriterlerin farklı küme altındaki kriterlerle olan öz vektör değerlerinin hesaplanması gerekir. Dış bağımlılıklardan elde edilen değerler, etkilenen kritere ait sütun içinde ilgili yere yazılır. Daha sonra önceden bulunan, etkileyen kümenin ağırlı̆̆ ile çarpılarak kriterin stokastik sütun içindeki değeri bulunmuş olur. İç bağımlılıklarda olduğu gibi dış bağımlılıkların da ikili karşılaştırma matris işlem sonuçları aşağıda verilmiştir. Ek 1-3'te satırdaki kriter etkilenen, sütundaki kriterler etkileyen kriterleri göstermektedir. Her matrisin tutarlılık oranı 0,1 değerinden küçük çıkmıştır.

\section{Adım 3: Süper-Matris Oluşumu (Structuring of Super Matrix)}

Ek 1'de kriterlerin amaç ve birbirleri ile ilgili öz vektör değerleri bulunduktan sonra oluşturulan ağırlıklandırılmamış süpermatris verilmiştir. Ağırlıklandırılmamış süpermatriste sütun toplamları birden büyüktür. Bu sütunların stokastik hale getirilmesi yani sütun toplamının 1 olması için sütunlar daha önce elde edilen küme ağırlıkları ile çarpılır ve Ek 2'deki ağırlıklandırılmış süpermatris elde edilmiştir. Kriter ağırlıklarının bulunması için yapılacak son işlem ağırlıklandırılmış ve stokastik hale getirilmiş olan süpermatrisin satırlarının durağan hale gelinceye kadar kuvvetinin alınmasıdır. Bu işlem sonucunda elde edilmiş olan limit süpermatris Ek 3'te görülmektedir.

AAS'den elde ettiğimiz sonuçlar Çizelge 2'de görülmektedir. Bu sonuçlara göre $\% 16,28$ değeri ile amaca yani en iyi elektrik dağıtım yolunu bulmak için en yüksek etkiye sahip kriter "kapalı alanların korunması" ile ilgili kriteridir. Limit süper matristen elde ettiğimiz değerlere göre yoğun tarım bölgesi yani seralar, tarihi yapılar, sel havzası, gelişmeye açık göletler ve hayvan koruma alanları etki değeri 0 
olmasına rağmen bu bölgeler yasak bölgeler içerisinde bulunduğundan kararımızı dolaylı olarak etkileyecektir.

\subsection{Alternatif Güzergâhların Belirlenmesi (Determination of Alternative Routes)}

Temel kriterleri göz önüne alarak (Binaların Korunması, Mühendislik İhtiyaçlarının Karşılanması, Doğal Çevrenin Korunması, Kombine Bakış Açısı) 4 alternatif güzergâh değerlendirmeye alınmıştır ve bu güzergâhlar Şekil 4 'te verilmiştir.

3.5. Alternatif Güzergahların Değerlendirilmesi (Evaluation of Alternative Routes)

Alternatif güzergâhların değerlendirilmesi işlemi büyük bir dikkat ve titizlikle yapılmalıdır. Alternatif güzergâhların değerlendirilmesi kararını etkileyen kriterlerin çeşitli ve bazılarının sayısal olmayışı değerlendirmeyi güçleştirmektedir. Bu tip problemleri çözmek için kullanılan yöntemlerden biri de Faktör Ağırlıklandırma Yöntemidir [17].

Çizelge 2. Limit Süper Matristen Elde Edilen Kriter Ağırlıkları (Criteria Weights Obtained from Limit Super Matrix)

\begin{tabular}{|l|c|c|}
\hline Kriter & Ağırlık & Yüzde Ağırlıklar \\
\hline Kapalı Alanlar & 0,1629 & 16,29 \\
\hline Alan Kullanımı & 0,1513 & 15,13 \\
\hline Düzgün Altyapı & 0,1301 & 13,01 \\
\hline Kırış Açısı & 0,1298 & 12,98 \\
\hline Eğim & 0,1098 & 10,98 \\
\hline Halka Açık Alanlar & 0,0977 & 9,77 \\
\hline Gelişme Açı Bölgeler & 0,0659 & 6,59 \\
\hline Bina Yoğunluğu & 0,0651 & 6,51 \\
\hline Önemli Hatlara Yakınlık & 0,0476 & 4,76 \\
\hline Binalara Yakınlık & 0,0399 & 3,99 \\
\hline Gelişmeye Açık Gölet & 0 & 0 \\
\hline Tarihi Yapılar & 0 & 0 \\
\hline Hayvan Koruma Alanlar & 0 & 0 \\
\hline Sel havzası & 0 & 0 \\
\hline Su Adası & 0 & 0 \\
\hline Yoğun Tarım & 0 & 0 \\
\hline
\end{tabular}

Alternatif güzergâhların değerlendirilmesinde faktör ağırlıklandırma yönteminin adımları aşağıdaki gibi uygulanmıştır.

1) İlgili kriterlerin listesi Çizelge 3'de görüldüğü gibi oluşturulur.

2) Her bir kritere, güzergâhın amaçlarındaki nispi önemini yansıtacak şekilde bir ağırlık atanması AAS ile bulunur.

3) Her bir kriter için 1-10 skalası (1 uygun olmayan, 10 en uygun) geliştirilir

4) Her bir alternatif güzergâha, her bir kriter için adım 3 deki skalayı kullanarak uzman skoru Çizelge 6'daki gibi belirlenir.

5) Her bir kriter için ağırlıkları skorla çarpılır ve her bir alternatif güzergâh için toplam skor Çizelge 3'deki gibi bulunur.

6) Toplam skoru en fazla olan alternatif güzergâh önerilir. 
Çizelge 3'e göre FA Yöntemi ile A, B, C ve D güzergâhları değerlendirilmiş ve Şekil 4'te görüldüğü gibi Selçuk Üniversitesi için en iyi güzergâhın D güzergâh olduğu belirlenmiştir. Alternatif sırası D-B-CA olarak belirlenmiştir.

Çizelge 3. Alternatiflerin Karşılaştırması (The Comparison of Alternatives)

\begin{tabular}{|l|c|c|c|c|c|c|c|c|c|}
\hline Kriter & Ağırlık & A & B & C & D & A & B & C & D \\
\hline Kapalı Alanlar & 0,1629 & 3 & 7 & 7 & 4 & 0,489 & 1,140 & 1,140 & 0,651 \\
\hline Alan Kullanımı & 0,1513 & 3 & 5 & 1 & 7 & 0,454 & 0,757 & 0,151 & 1,059 \\
\hline Düzgün Altyapı & 0,1301 & 7 & 1 & 7 & 7 & 0,911 & 0,130 & 0,911 & 0,911 \\
\hline Kırış Açısı & 0,1298 & 1 & 10 & 1 & 7 & 0,130 & 1,298 & 0,130 & 0,908 \\
\hline Ĕgim & 0,1098 & 7 & 1 & 7 & 5 & 0,769 & 0,110 & 0,769 & 0,549 \\
\hline Halka Açı Alanlar & 0,0977 & 3 & 5 & 7 & 3 & 0,293 & 0,488 & 0,684 & 0,293 \\
\hline Gelişme Açık Bölgeler & 0,0659 & 1 & 7 & 1 & 5 & 0,066 & 0,461 & 0,066 & 0,329 \\
\hline Bina Yoğunluğu & 0,0651 & 1 & 7 & 1 & 7 & 0,065 & 0,456 & 0,065 & 0,456 \\
\hline Önemli Hatlara Yakınlık & 0,0476 & 7 & 3 & 7 & 7 & 0,333 & 0,143 & 0,333 & 0,333 \\
\hline Binalara Yakınlık & 0,0399 & 5 & 3 & 1 & 7 & 0,199 & 0,120 & 0,040 & 0,279 \\
\hline Gelişmeye Açık Gölet & 0 & 3 & 4 & 7 & 5 & 0 & 0 & 0 & 0 \\
\hline Tarihi Yapılar & 0 & 1 & 3 & 2 & 4 & 0 & 0 & 0 & 0 \\
\hline Hayvan Koruma Alanlar & 0 & 3 & 5 & 7 & 5 & 0 & 0 & 0 & 0 \\
\hline Sel havzası & 0 & 5 & 3 & 3 & 5 & 0 & 0 & 0 & 0 \\
\hline Su Adası & 0 & 7 & 5 & 8 & 6 & 0 & 0 & 0 & 0 \\
\hline Yoğun Tarım & 0 & 7 & 6 & 7 & 5 & 0 & 0 & 0 & 0 \\
\hline TOPLAM & & & & & & 3,708 & 5,102 & 4,288 & 5,769 \\
\hline
\end{tabular}




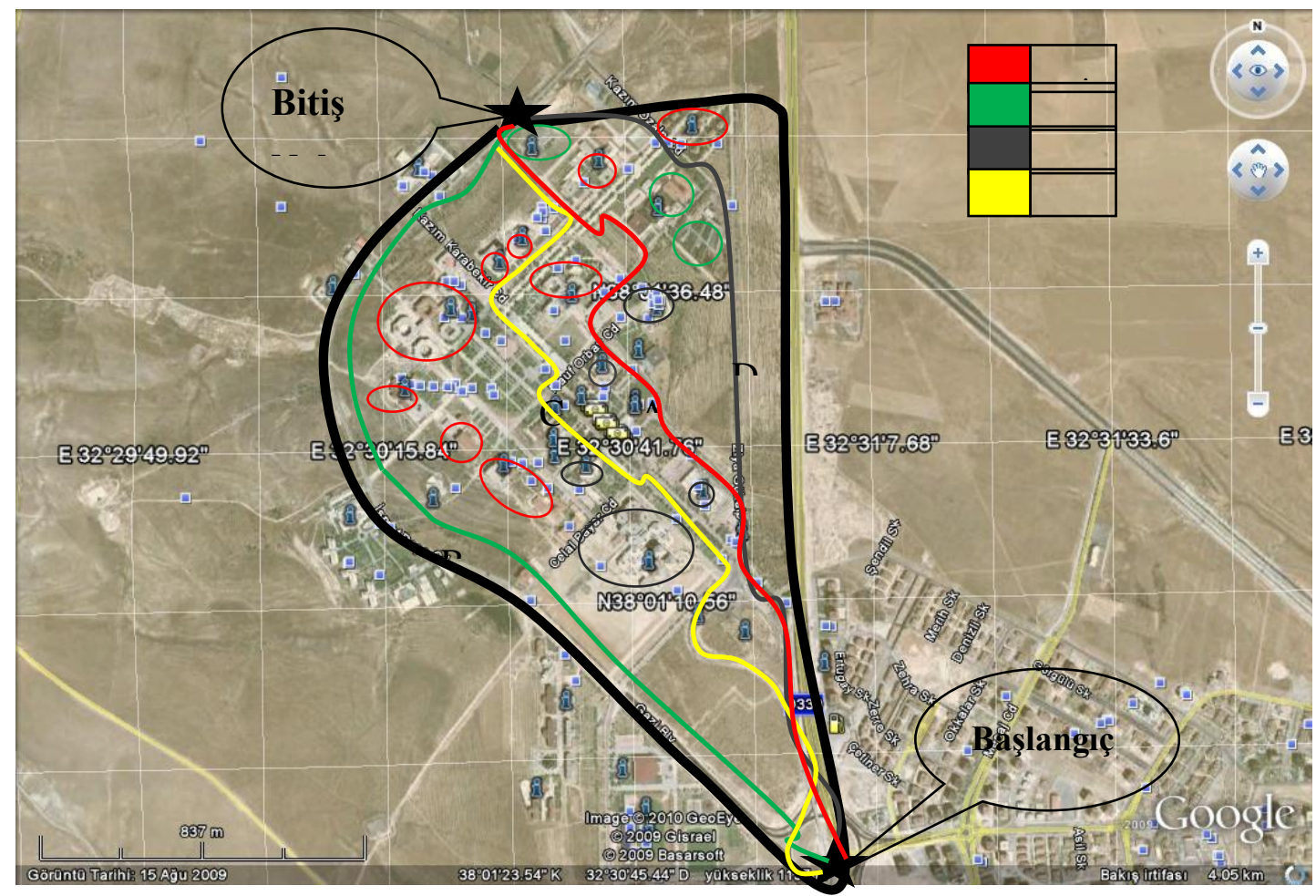

Şekil 4. Çeşitli Bakış Açılarından Alternatif Güzergâhlar (Alternative Routes from Different Perspectives)

\section{SONUÇ (CONCLUSION)}

Çalışmada oluşturulan karar modeli üç ana ve on altı alt kriterden oluşmaktadır. Kriterler arası bağlar belirlendikten sonra, karşılaştırma matrislerine değerler yerleştirilerek karşılaştırmalar yapılmıştır. Matrislerdeki değerler, ağ yapısı oluşturulduktan sonra yapılan hesaplamalarla ağırlıklandırılmamış süper-matris, ağırlıklandırılmış süper-matris, limit matris elde edilmiştir.

$\mathrm{Bu}$ matrislerden elde edilen bulgulara göre en iyi dağıtım hattının seçilmesi açısından en etkili kriter \%16,28 ile kapalı alanların korunması ile ilgili kriter olarak belirlenmiştir.

Kriterlerin ağırlıkları belirlendikten sonra 3 ana kriter ve bunların kombinasyonu olan bir kriter göz önüne alınarak dört alternatif güzergâh geliştirilmiştir. Bu alternatif güzergâhlar Faktör Ağırlıklama Yöntemi kullanılarak her bir kriter en uygundan uygun olmayana doğru 1-10 skalası kullanılarak ölçeklendirilmiş ve AAS elde ettiğimiz katsayılarla çarpılarak ağırlıklandırılmıştır. En fazla ağırlığa sahip yol en uygun yol olduğu için D yolu seçilmiştir. D yolunun atamasında ise binaların korunması yani insanların yaşam alanlarının korunması bizim için öncelikli kriter olmuştur. D yolu bazı kriterlere göre daha az avantajlı olmasına rağmen kararı daha çok etkileyen kriterler bakımından daha avantajlı olması D yolunun seçilmesinde önem teşkil etmiştir.

Sonraki çalışmalarda aynı problem bulanıklaştırılarak ve başka ÇKKV yöntemleri ile çözülüp elde edilen sonuçlar, mevcut problemin sonuçlarıyla kıyaslanabilir. 


\section{KAYNAKLAR (REFERENCES)}

Gill, R. S., Jewell, W., Grossardt, T. ve Bailey, K., "Landscape Features in Transmission Line Routing", IEEE, 1-5, 2006.

Jewell, W., Grossardt, T. ve Bailey, K., "Introduction to Electric Transmission Line Routing using a Decision-Landscape Based Methodology", IEEE, 379-382, 2006.

Demircan S., Çoklu Etmenler Kullanılarak Enerji Nakil Hattı Güzergâh Optimizasyonu, Yüksek Lisans Tezi, Selçuk Üniversitesi, Fen Bilimleri Enstitüsü, 2009,

Saaty T. L. ve Vargas L. G., Decision Making with the Analytic Network Process: Economic, Political, Social and Technological Applications with Benefits, Opportunities, Costs and Risks, MA: Springer Science+Business Media, LLC, Boston, 2006.

Önüt, S., Tuzkaya, U. R. ve Kemer, B., "An analytical Network Process Approach to the Choice of Hospital Location", Sigma, 25, 1-13, 2008.

Saaty T.L., The Analytic Network Process: Decision Making With Dependence And Feedback, RWS Publ., Pittsburg, 2001.

Yüksel I. ve Dağdeviren M., “Using The Analytic Network Process (ANP) In A SWOT Analysis-A Case Study For A Textile Firm", Information Sciences, 177, 3364-3382, 2007.

Cheng E.W.L. ve Li H., "Contractor Selection Using ANP", Construction Management and Economics, 22, 1021-1032, 2004.

Meade L.M. ve Sarkis J., " Analyzing Organizational Project Alternatives for Agile Manufacturing Process: An Analytical Network Approach", Int. J.Prod. Res, 37, 2, 241-261, 1999.

Chung S.H., Lee A.H.I. ve Pearn W.L., "Analytic Network Process Approach for Product Mix Planning in Semiconductor Fabricator", Int. J. Production Economics, 96, 15-36, 2005.

Aksakal, E. ve Dağdeviren, M., "An Integrated Approach for Personel Selection with DEMATELand ANP Methods", J. Fac. Eng. Arch. Gazi Univ., Vol 25, No 4, 905-913, 2010.

Dağdeviren, M., Dönmez, N. ve Kurt, M., “Developing a New Model for Supplier Evaluation Process for a Company and its Application", J. Fac. Eng. Arch. Gazi Univ., Vol 21, No 2, 247-255, 2006.

Dağdeviren, M., Eraslan, E. ve Kurt, M., “A Model to Determine Overall Workload Level of Workers and its Applications", J. Fac. Eng. Arch. Gazi Univ., Vol 20, No 4, 517-525, 2005.

Bağ, N., Özdemir, M. ve Eren, T., “0-1 Hedef Programlama ve ANP Yöntemi ile Hemşire Çizelgeleme Problemi Çözümü" International Journal of Engineering Research and Development, Vol 4, No 1, 2-6, 2012.

Görgülü İ., Korkmaz M. ve Eren T., “Analitik ağ prosesi ve TOPSIS yöntemleri ile optimal yatırım stratejisi seçimi", Sigma Mühendislik ve Fen Bilimleri Dergisi, Vol 31, No 2, 203-213, 2013.

Özbek, A. ve Eren, T., "Analitik A ̆̆ Süreci Yaklaşımılla Üçüncü Parti Lojistik (3PL) FirmaSeçimi”, Atatürk Üniversitesi İ.İ.B.F. Dergisi, Vol 27, No 1, 95-113, 2013.

Su, B. A. ve Aslan, D., Tesis Planlama, Dokuz Eylül Üniversitesi Mühendislik Fakültesi Yayınları No:201, İzmir, 1997.

Houston, G. ve Johnson, C, EPRI-GTC Overhead Electric Transmission Line Siting Methodology, Technical Report, 2006. 
Ek 1. Ağırlıklandırılmamış Süper Matris (Unweighted Super Matrix)

\begin{tabular}{|c|c|c|c|c|c|c|c|c|c|c|c|c|c|c|c|c|c|}
\hline & & $\begin{array}{c}\text { Alan } \\
\text { Kullanımı } \\
\end{array}$ & $\begin{array}{c}\text { Bina } \\
\text { Yoğunluğu }\end{array}$ & $\begin{array}{l}\text { Binalara } \\
\text { Yakınlık } \\
\end{array}$ & $\begin{array}{c}\text { Gelişime } \\
\text { Açık } \\
\text { Bölgeler }\end{array}$ & $\begin{array}{l}\text { Gelişmeye } \\
\text { Açık Gölet }\end{array}$ & $\begin{array}{l}\text { Tarihi } \\
\text { Yapılar }\end{array}$ & $\begin{array}{c}\text { Önemli } \\
\text { Hatlara } \\
\text { Yakınlık }\end{array}$ & \begin{tabular}{|c|} 
Halka \\
Açık \\
Alanlar \\
\end{tabular} & $\begin{array}{c}\text { Hayvan } \\
\text { Koruma } \\
\text { Alanlar }\end{array}$ & $\begin{array}{c}\text { Kapali } \\
\text { Alanlar }\end{array}$ & $\begin{array}{c}\text { Sel } \\
\text { Havzas1 }\end{array}$ & $\begin{array}{c}\mathrm{Su} \\
\text { Adas1 } \\
\end{array}$ & $\begin{array}{l}\text { Düzgün } \\
\text { Altyap1 }\end{array}$ & Ĕgim & $\begin{array}{l}\text { Kırış } \\
\text { Açısı }\end{array}$ & $\begin{array}{l}\text { Yoğun } \\
\text { Tarım }\end{array}$ \\
\hline \multirow{7}{*}{ 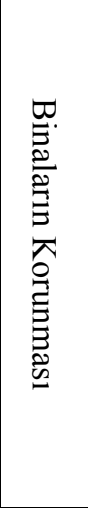 } & Alan Kullanımı & 0,00 & 0,17 & 0,17 & 0,56 & 0,00 & 0,00 & 1,00 & 0,64 & 0,00 & 0,17 & 0,00 & 0,00 & 1,00 & 0,50 & 0,20 & 0,00 \\
\hline & Bina Yoğunluğu & 0,59 & 0,00 & 0,83 & 0,19 & 0,00 & 0,00 & 0,00 & 0,26 & 0,00 & 0,00 & 0,00 & 0,00 & 0,00 & 0,00 & 0,09 & 0,00 \\
\hline & Binalara Yakınlık & 0,11 & 0,83 & 0,00 & 0,06 & 0,00 & 0,00 & 0,00 & 0,10 & 0,00 & 0,00 & 0,00 & 0,00 & 0,00 & 0,00 & 0,05 & 0,00 \\
\hline & $\begin{array}{|ll|}\text { Gelişime } & \text { Açık } \\
\text { Bölgeler } & \\
\end{array}$ & 0,05 & 0,00 & 0,00 & 0,00 & 0,00 & 0,00 & 0,00 & 0,00 & 0,00 & 0,83 & 0,00 & 0,00 & 0,00 & 0,50 & 0,00 & 0,00 \\
\hline & $\begin{array}{l}\text { Gelişmeye Açık } \\
\text { Gölet }\end{array}$ & 0,00 & 0,00 & 0,00 & 0,00 & 0,00 & 0,00 & 0,00 & 0,00 & 0,00 & 0,00 & 0,00 & 0,00 & 0,00 & 0,00 & 0,00 & 0,00 \\
\hline & Tarihi Yapılar & 0,00 & 0,00 & 0,00 & 0,00 & 0,00 & 0,00 & 0,00 & 0,00 & 0,00 & 0,00 & 0,00 & 0,00 & 0,00 & 0,00 & 0,00 & 0,00 \\
\hline & \begin{tabular}{|lr} 
Önemli & Hatlara \\
Yakınlık & \\
\end{tabular} & 0,26 & 0,00 & 0,00 & 0,19 & 0,00 & 0,00 & 0,00 & 0,00 & 0,00 & 0,00 & 0,00 & 0,00 & 0,00 & 0,00 & 0,66 & 0,00 \\
\hline \multirow{5}{*}{ 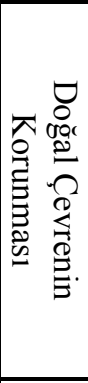 } & $\begin{array}{|ll|}\text { Halka } & \text { Aç1k } \\
\text { Alanlar } & \\
\end{array}$ & 0,17 & 0,00 & 0,00 & 0,00 & 0,00 & 0,00 & 0,00 & 0,00 & 0,00 & 1,00 & 0,00 & 0,00 & 0,17 & 0,17 & 0,50 & 0,00 \\
\hline & $\begin{array}{|ll|}\begin{array}{l}\text { Hayvan } \\
\text { Alanlar }\end{array} & \text { Koruma } \\
\end{array}$ & 0,00 & 0,00 & 0,00 & 0,00 & 0,00 & 0,00 & 0,00 & 0,00 & 0,00 & 0,00 & 0,00 & 0,00 & 0,00 & 0,00 & 0,00 & 0,00 \\
\hline & Kapalı Alanlar & 0,83 & 0,00 & 0,00 & 0,00 & 0,00 & 0,00 & 0,00 & 1,00 & 0,00 & 0,00 & 0,00 & 0,00 & 0,83 & 0,83 & 0,50 & 1,00 \\
\hline & Sel Havzası & 0,00 & 0,00 & 0,00 & 0,00 & 0,00 & 0,00 & 0,00 & 0,00 & 0,00 & 0,00 & 0,00 & 0,00 & 0,00 & 0,00 & 0,00 & 0,00 \\
\hline & Su Adası & 0,00 & 0,00 & 0,00 & 0,00 & 0,00 & 0,00 & 0,00 & 0,00 & 0,00 & 0,00 & 0,00 & 0,00 & 0,00 & 0,00 & 0,00 & 0,00 \\
\hline \multirow{4}{*}{ 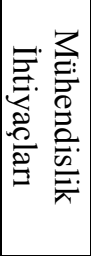 } & Düzgün Altyap1 & 0,11 & 0,46 & 0,86 & 0,50 & 0,00 & 0,00 & 0,14 & 0,14 & 0,00 & 0,14 & 0,00 & 0,00 & 0,00 & 0,46 & 1,00 & 0,50 \\
\hline & Eğim & 0,11 & 0,46 & 0,14 & 0,50 & 0,00 & 0,00 & 0,14 & 0,14 & 0,00 & 0,14 & 0,00 & 0,00 & 0,86 & 0,46 & 0,00 & 0,50 \\
\hline & Kırış Açıs1 & 0,78 & 0,08 & 0,00 & 0,00 & 0,00 & 0,00 & 0,71 & 0,71 & 0,00 & 0,71 & 0,00 & 0,00 & 0,14 & 0,08 & 0,00 & 0,00 \\
\hline & Yoğun Tarım & 0,00 & 0,00 & 0,00 & 0,00 & 0,00 & 0,00 & 0,00 & 0,00 & 0,00 & 0,00 & 0,00 & 0,00 & 0,00 & $0,00 \mid$ & $0,00 \mid$ & 0,00 \\
\hline
\end{tabular}


Ek 2. Ağırlıklandırılmış Süper Matris (Weighted Super Matrix)

\begin{tabular}{|c|c|c|c|c|c|c|c|c|c|c|c|c|c|c|c|c|c|}
\hline & & \multicolumn{7}{|c|}{ Binaların Korunması } & \multicolumn{5}{|c|}{ Doğal Çevrenin Korunması } & \multicolumn{4}{|c|}{$\begin{array}{l}\text { Mühendislik İhtiyaçlarının } \\
\text { Karşılanmas }\end{array}$} \\
\hline & & $\begin{array}{c}\text { Alan } \\
\text { Kullanımı } \\
\end{array}$ & \begin{tabular}{|c|} 
Bina \\
Yoğunluğu \\
\end{tabular} & $\begin{array}{l}\text { Binalara } \\
\text { Yakınlık } \\
\end{array}$ & $\begin{array}{l}\text { Gelişime } \\
\text { Açık } \\
\text { Bölgeler } \\
\end{array}$ & $\begin{array}{l}\text { Gelişmeye } \\
\text { Açı Gölet }\end{array}$ & $\begin{array}{l}\text { Tarihi } \\
\text { Yapılar }\end{array}$ & $\begin{array}{c}\text { Önemli } \\
\text { Hatlara } \\
\text { Yakınlık } \\
\end{array}$ & $\begin{array}{l}\text { Halka } \\
\text { Açık } \\
\text { Alanlar } \\
\end{array}$ & $\begin{array}{l}\text { Hayvan } \\
\text { Koruma } \\
\text { Alanlar } \\
\end{array}$ & $\begin{array}{l}\text { Kapalı } \\
\text { Alanlar }\end{array}$ & $\begin{array}{c}\text { Sel } \\
\text { Havzasi }\end{array}$ & $\begin{array}{c}\mathrm{Su} \\
\text { Adas1 }\end{array}$ & $\begin{array}{l}\text { Düzgün } \\
\text { Altyap1 }\end{array}$ & Eğim & $\begin{array}{l}\text { Kırıș } \\
\text { Açısi }\end{array}$ & $\begin{array}{l}\text { Yoğun } \\
\text { Tarım }\end{array}$ \\
\hline \multirow{7}{*}{ 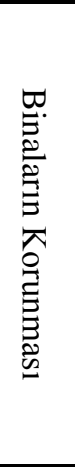 } & Alan Kullanımı & 0,00 & 0,08 & 0,08 & 0,28 & 0,00 & 0,00 & 0,50 & 0,21 & 0,00 & 0,06 & 0,00 & 0,00 & 0,33 & 0,17 & 0,07 & 0,00 \\
\hline & Bina Yoğunluğu & 0,20 & 0,00 & 0,42 & 0,09 & 0,00 & 0,00 & 0,00 & 0,09 & 0,00 & 0,00 & 0,00 & 0,00 & 0,00 & 0,00 & 0,03 & 0,00 \\
\hline & \begin{tabular}{|l|} 
Binalara \\
Yakınlık \\
\end{tabular} & 0,04 & 0,42 & 0,00 & 0,03 & 0,00 & 0,00 & 0,00 & 0,03 & 0,00 & 0,00 & 0,00 & 0,00 & 0,00 & 0,00 & 0,02 & 0,00 \\
\hline & \begin{tabular}{|l} 
Gelişime Açık \\
Bölgeler
\end{tabular} & 0,02 & 0,00 & 0,00 & 0,00 & 0,00 & 0,00 & 0,00 & 0,00 & 0,00 & 0,28 & 0,00 & 0,00 & 0,00 & 0,17 & 0,00 & 0,00 \\
\hline & $\begin{array}{l}\text { Gelişmeye Açık } \\
\text { Gölet }\end{array}$ & 0,00 & 0,00 & 0,00 & 0,00 & 0,00 & 0,00 & 0,00 & 0,00 & 0,00 & 0,00 & 0,00 & 0,00 & 0,00 & 0,00 & 0,00 & 0,00 \\
\hline & Tarihi Yapılar & 0,00 & 0,00 & 0,00 & 0,00 & 0,00 & 0,00 & 0,00 & 0,00 & 0,00 & 0,00 & 0,00 & 0,00 & 0,00 & 0,00 & 0,00 & 0,00 \\
\hline & $\begin{array}{l}\text { Önemli Hatlara } \\
\text { Yakınlık }\end{array}$ & 0,09 & 0,00 & 0,00 & 0,09 & 0,00 & 0,00 & 0,00 & 0,00 & 0,00 & 0,00 & 0,00 & 0,00 & 0,00 & 0,00 & 0,22 & 0,00 \\
\hline \multirow{5}{*}{ 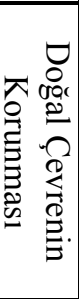 } & \begin{tabular}{|ll} 
Halka & Açık \\
Alanlar & \\
\end{tabular} & 0,06 & 0,00 & 0,00 & 0,00 & 0,00 & 0,00 & 0,00 & 0,00 & 0,00 & 0,33 & 0,00 & 0,00 & 0,06 & 0,06 & 0,17 & 0,00 \\
\hline & $\begin{array}{l}\text { Hayvan Koruma } \\
\text { Alanlar }\end{array}$ & 0,00 & 0,00 & 0,00 & 0,00 & 0,00 & 0,00 & 0,00 & 0,00 & 0,00 & 0,00 & 0,00 & 0,00 & 0,00 & 0,00 & 0,00 & 0,00 \\
\hline & Kapalı Alanlar & 0,28 & 0,00 & 0,00 & 0,00 & 0,00 & 0,00 & 0,00 & 0,33 & 0,00 & 0,00 & 0,00 & 0,00 & 0,28 & 0,28 & 0,17 & 0,50 \\
\hline & Sel Havzası & 0,00 & 0,00 & 0,00 & 0,00 & 0,00 & 0,00 & 0,00 & 0,00 & 0,00 & 0,00 & 0,00 & 0,00 & 0,00 & 0,00 & 0,00 & 0,00 \\
\hline & Su Adas1 & 0,00 & 0,00 & 0,00 & 0,00 & 0,00 & 0,00 & 0,00 & 0,00 & 0,00 & 0,00 & 0,00 & 0,00 & 0,00 & 0,00 & 0,00 & 0,00 \\
\hline \multirow{4}{*}{ 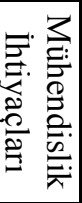 } & Düzgün Altyap1 & 0,04 & 0,23 & 0,43 & 0,25 & 0,00 & 0,00 & 0,07 & 0,05 & 0,00 & 0,05 & 0,00 & 0,00 & 0,00 & 0,15 & 0,33 & 0,25 \\
\hline & Ĕ̆gim & 0,04 & 0,23 & 0,07 & 0,25 & 0,00 & 0,00 & 0,07 & 0,05 & 0,00 & 0,05 & 0,00 & 0,00 & 0,29 & 0,15 & 0,00 & 0,25 \\
\hline & Kırış Açı1s1 & 0,26 & 0,04 & 0,00 & 0,00 & 0,00 & 0,00 & 0,36 & 0,24 & 0,00 & 0,24 & 0,00 & 0,00 & 0,05 & 0,03 & 0,00 & 0,00 \\
\hline & Yoğun Tarım & 0,00 & 0,00 & 0,00 & 0,00 & 0,00 & 0,00 & 0,00 & 0,00 & 0,00 & 0,00 & 0,00 & 0,00 & 0,00 & 0,00 & 0,00 & 0,00 \\
\hline
\end{tabular}


Ek 3. Limit Süper Matris (Limit Super Matrix)

\begin{tabular}{|c|c|c|c|c|c|c|c|c|c|c|c|c|c|c|c|c|c|}
\hline & & \multicolumn{7}{|c|}{ Binaların Korunması } & \multicolumn{5}{|c|}{ Doğal Çevrenin Korunmas1 } & \multicolumn{4}{|c|}{ Mühendislik İhtiyaçlarının Karşılanması } \\
\hline & & \begin{tabular}{|c|} 
Alan \\
Kullanımı \\
\end{tabular} & \begin{tabular}{|c|} 
Bina \\
Yoğunluğu \\
\end{tabular} & $\begin{array}{l}\text { Binalara } \\
\text { Yakınlık } \\
\end{array}$ & \begin{tabular}{|c|} 
Gelişime \\
Açık \\
Bölgeler \\
\end{tabular} & $\begin{array}{l}\text { Gelişmeye } \\
\text { Açı Gölet } \\
\end{array}$ & $\begin{array}{c}\text { Tarihi } \\
\text { Yapilar }\end{array}$ & $\begin{array}{c}\text { Önemli } \\
\text { Hatlara } \\
\text { Yakınlık } \\
\end{array}$ & $\begin{array}{c}\text { Halka } \\
\text { Açık } \\
\text { Alanlar } \\
\end{array}$ & $\begin{array}{l}\text { Hayvan } \\
\text { Koruma } \\
\text { Alanlar } \\
\end{array}$ & $\begin{array}{c}\text { Kapalı } \\
\text { Alanlar }\end{array}$ & $\begin{array}{c}\text { Sel } \\
\text { Havzas1 }\end{array}$ & $\begin{array}{c}\mathrm{Su} \\
\text { Adas1 } \\
\end{array}$ & $\begin{array}{l}\text { Düzgün } \\
\text { Altyap1 }\end{array}$ & Eğim & $\begin{array}{l}\text { Kırış } \\
\text { Açıs1 }\end{array}$ & $\begin{array}{l}\text { Yoğun } \\
\text { Tarım }\end{array}$ \\
\hline \multirow{7}{*}{ 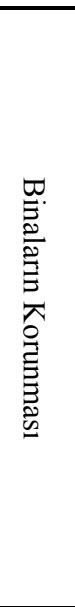 } & \begin{tabular}{|l|} 
Alan \\
Kullanımı \\
\end{tabular} & 0,15 & 0,15 & 0,15 & 0,15 & 0,00 & 0,00 & 0,15 & 0,15 & 0,00 & 0,15 & 0,00 & 0,00 & 0,15 & 0,15 & 0,15 & 0,15 \\
\hline & \begin{tabular}{|l|} 
Bina \\
Yoğunluğu
\end{tabular} & 0,07 & 0,07 & 0,07 & 0,07 & 0,00 & 0,00 & 0,07 & 0,07 & 0,00 & 0,07 & 0,00 & 0,00 & 0,07 & 0,07 & 0,07 & 0,07 \\
\hline & $\begin{array}{l}\text { Binalara } \\
\text { Yakınlık }\end{array}$ & 0,04 & 0,04 & 0,04 & 0,04 & 0,00 & 0,00 & 0,04 & 0,04 & 0,00 & 0,04 & 0,00 & 0,00 & 0,04 & 0,04 & 0,04 & 0,04 \\
\hline & \begin{tabular}{|l|} 
Gelişime \\
Açı \\
Bölgeler \\
\end{tabular} & 0,07 & 0,07 & 0,07 & 0,07 & 0,00 & 0,00 & 0,07 & 0,07 & 0,00 & 0,07 & 0,00 & 0,00 & 0,07 & 0,07 & 0,07 & 0,07 \\
\hline & $\begin{array}{l}\text { Gelişmeye } \\
\text { Açı Gölet }\end{array}$ & 0,00 & 0,00 & 0,00 & 0,00 & 0,00 & 0,00 & 0,00 & 0,00 & 0,00 & 0,00 & 0,00 & 0,00 & 0,00 & 0,00 & 0,00 & 0,00 \\
\hline & \begin{tabular}{|l|} 
Tarihi \\
Yap1lar
\end{tabular} & 0,00 & 0,00 & 0,00 & 0,00 & 0,00 & 0,00 & 0,00 & 0,00 & 0,00 & 0,00 & 0,00 & 0,00 & 0,00 & 0,00 & 0,00 & 0,00 \\
\hline & \begin{tabular}{|l} 
Önemli \\
Hatlara \\
Yakınlık
\end{tabular} & 0,05 & 0,05 & 0,05 & 0,05 & 0,00 & 0,00 & 0,05 & 0,05 & 0,00 & 0,05 & 0,00 & 0,00 & 0,05 & 0,05 & 0,05 & 0,05 \\
\hline \multirow{5}{*}{ 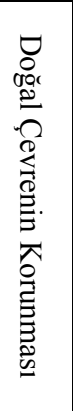 } & \begin{tabular}{|l|} 
Halka \\
Açık \\
Alanlar
\end{tabular} & 0,10 & 0,10 & 0,10 & 0,10 & 0,00 & 0,00 & 0,10 & 0,10 & 0,00 & 0,10 & 0,00 & 0,00 & 0,10 & 0,10 & 0,10 & 0,10 \\
\hline & \begin{tabular}{|l|} 
Hayvan \\
Koruma \\
Alanlar \\
\end{tabular} & 0,00 & 0,00 & 0,00 & 0,00 & 0,00 & 0,00 & 0,00 & 0,00 & 0,00 & 0,00 & 0,00 & 0,00 & 0,00 & 0,00 & 0,00 & 0,00 \\
\hline & $\begin{array}{l}\text { Kapalı } \\
\text { Alanlar }\end{array}$ & 0,16 & 0,16 & 0,16 & 0,16 & 0,00 & 0,00 & 0,16 & 0,16 & 0,00 & 0,16 & 0,00 & 0,00 & 0,16 & 0,16 & 0,16 & 0,16 \\
\hline & \begin{tabular}{|l} 
Sel \\
Havzas1
\end{tabular} & 0,00 & 0,00 & 0,00 & 0,00 & 0,00 & 0,00 & 0,00 & 0,00 & 0,00 & 0,00 & 0,00 & 0,00 & 0,00 & 0,00 & 0,00 & 0,00 \\
\hline & Su Adası & 0,00 & 0,00 & 0,00 & 0,00 & 0,00 & 0,00 & 0,00 & 0,00 & 0,00 & 0,00 & 0,00 & 0,00 & 0,00 & 0,00 & 0,00 & 0,00 \\
\hline \multirow{4}{*}{ 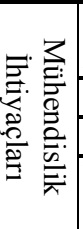 } & $\begin{array}{l}\text { Düzgün } \\
\text { Altyap1 }\end{array}$ & 0,13 & 0,13 & 0,13 & 0,13 & 0,00 & 0,00 & 0,13 & 0,13 & 0,00 & 0,13 & 0,00 & 0,00 & 0,13 & 0,13 & 0,13 & 0,13 \\
\hline & Ĕ̆im & 0,11 & 0,11 & 0,11 & 0,11 & 0,00 & 0,00 & 0,11 & 0,11 & 0,00 & 0,11 & 0,00 & 0,00 & 0,11 & 0,11 & 0,11 & 0,11 \\
\hline & Kırış Açıs1 & 0,13 & 0,13 & 0,13 & 0,13 & 0,00 & 0,00 & 0,13 & 0,13 & 0,00 & 0,13 & 0,00 & 0,00 & 0,13 & 0,13 & 0,13 & 0,13 \\
\hline & $\begin{array}{l}\text { Yoğun } \\
\text { Tarım }\end{array}$ & 0,00 & 0,00 & 0,00 & 0,00 & 0,00 & 0,00 & 0,00 & 0,00 & 0,00 & 0,00 & 0,00 & 0,00 & 0,00 & 0,00 & 0,00 & 0,00 \\
\hline
\end{tabular}

